SIIENCE \& HUMANITIES JOURNAL

VOLUME 9, 2009. PP. 88-96

\title{
ANALYSIS OF THE FUNCTIONALITY OF ALAYON IN THE DEVELOPMENT AND TRANSFER OF TECHNOLOGY AMONG UPLAND FARMERS IN REGION VIII*
}

\author{
Antonia Cecilia Y. Sandoval \\ Department of Community and Development Education \\ College of Education, Visayas State University \\ Visca, Baybay City, Leyte
}

\section{ABSTRACT}

The study sought to 1) trace the early beginnings of the alayon, 2) determine the alayon's role in the development and transfer of technology, 3) identify some needs and constraints to technology development and dissemination; and 4) identify and describe the common methods of technology transfer employed by the alayon.

A stratified multi-stage sampling was used to identify the respondents. A total of fifteen alayons with 167 members were studied using a focusedstructured interview.

Access to agricultural technology was gained by most farmers in addition to the economic and social benefits. Financial constraint was the most common problem felt.

Common methods employed by the alayon in the transfer of technology included informal conversation, training/seminar/farmer's class and actual field observation/documentation.

KEY WORDS: Alayon. Technology development. Technology transfer. Constraints

"This is the first study regarding alayon system, hence, no literature can be cited 


\section{INTRODUCTION}

In cognizance of the fact that more than $70 \%$ of the people are in the rural areas and that they comprise the bulk of the country's poor, development efforts must commence with them. This calls for an understanding of the various sectors of the populace. Organizations are instrumental to a nation's development. The choice of a development strategy would be easy if a sound knowledge or rural organizations operating in the locality is obtained. Such organizations can be utilized in the development of an agricultural community through technology generation and dissemination.

This study was proposed in recognition of the important role the alayon had performed in the development and transfer of technology to accelerate upland development. Contrary to institutionalized farmers group and the computer-based information technology as exemplified by the Open Academy for Philippine Agriculture (OPAPA), which provides farmers access through network and the internet, the alayon as an indigenous rural organization had served most rural households in various farm and non-farm activities propelled by the culture of cooperation, unity or oneness in the midst of scarce financial resources. It does not fill the gap but had proven to withstand the test of time as an effective indigenous tool in bringing about development.

The study focused on the member, hence, non-members were not included as reflected in its objectives. Non-inclusion of non-members is one of the limitations of the study.

\section{Objectives}

1. To trace the early beginning of the alayon and its characteristics;

2. To determine the alayon's role in the development and transfer of appropriate technology; 
3.To identify some needs and constraints encountered by the members in relation to technology development and dissemination; and

4. To identify and describe the appropriate and common methods of technology transfer effectively employed by the alayon groups.

\section{METHODOLOGY}

\section{Sampling Procedure}

Stratified, multi-stage random sampling was done in Region VIII to identify respondents of the study in consonance with the Department of Agriculture's priority coverage. From the region, two provinces were selected with five municipalities each. From each municipality, one barangay was purposively chosen. Leyte and Samar provinces were given priority because they satisfy the following criteria:

1. Accessible by land transportation.

2. Majority of the households are engaged in farming, and

3. Based on a preliminary survey, farmers have practiced and adhered to the alayon system to a great extent.

A total of fifteen upland barangay alayons were critically studied and analyzed (Table 1).

\section{Data Collection}

Prior to data collection, field interviewers were oriented on the questionnaire and trained on how to gather data.

Data collection instruments or schedules were prepared, standardized in the English language and translated into Cebuano and Waray. The translated instruments were pretested to determine their completeness and understandability. 
Table 1. Distribution of alayon members by province, municipality and barangay

\begin{tabular}{|c|c|c|c|}
\hline $\begin{array}{l}\text { Province/Municipality } \\
\text { Alayon Group }\end{array}$ & $\begin{array}{l}\text { Number } \\
\text { Reporting }\end{array}$ & $\begin{array}{l}\text { Percent } \\
(\%)\end{array}$ & \\
\hline A. Leyte & 70 & 42 & \\
\hline Baybay & 19 & 27 & \\
\hline Guadalupe & 15 & & 79 \\
\hline Patag & 4 & & 21 \\
\hline Hindang & 20 & 29 & \\
\hline Anolon 1 & 6 & & 30 \\
\hline Anolon 2 & 6 & & 30 \\
\hline Anolon 3 & 8 & & 40 \\
\hline Villaba & 31 & 44 & \\
\hline Cagnocot & 12 & & 39 \\
\hline Tabunoc & 19 & & 61 \\
\hline B. Southern Leyte & 6 & 4 & \\
\hline Bontoc & 6 & 100 & \\
\hline San Vicente & 6 & 100 & \\
\hline C. Western Samar & 76 & 45 & \\
\hline Gandara & 23 & 30 & \\
\hline Diaz & 10 & & 43 \\
\hline San Agustin & 13 & & 56 \\
\hline Pinabacdao & 53 & 70 & \\
\hline Pahug & 34 & & 64.2 \\
\hline Madalunot & 14 & & 26.4 \\
\hline Bugho & 5 & & 9.4 \\
\hline D. Northern Samar & 15 & 9 & , \\
\hline Pambujan & 15 & 100 & \\
\hline Doña Anecita & 12 & & 80 \\
\hline Cababto-an & 3 & & 20 \\
\hline Total & 167 & 100 & \\
\hline
\end{tabular}


A complete enumeration of the members of fifteen alayon groups/organizations in Region VIII was done. A total of 167 alayon members were interviewed.

\section{Methods of Analysis}

Descriptive statistics such as frequency counts, percentages, mean/averages and ranges were employed in the analysis of data.

\section{RESULTS AND DISCUSSION}

\section{The Study Area}

Seven municipalities were identified as the study areas: three in Leyte (Baybay, Hindang and Villaba); one in Southern Leyte (Bontoc); two in Western Samar (Ganadara \& Pinabacdao); and one in Northern Samar (Pambujan).

\section{The Alayon Member-Respondents}

A total of 167 alayon members served as respondents of the study. Table 1 reflects the alayon member-respondents by province, municipality and by barangay.

\section{Early Beginnings of Local Alayons}

The majority of the alayon member-respondents claimed that they have learned about alayon system at different times to start before the 1950 's up to the 1990's. All of the Cagnocot alayon group memberrespondents learned about the alayon system in 1980's, while a number said they have already known about the system in the late 1950's. In fact, half of the alayon member-respondents from Anolon $2(50 \%)$ and almost 63 percent (62.5\%) of Anolon 3 alayon member-respondents go farther in time to the years before the 1950's. In contrast, some alayon group 
member have learned about the alayon system just lately in the 1990's (Table 2).

Word does get around in the respondent's communities. The alayon member respondents learned about alayon system from their grandparents, parents, brothers/sisters, neighbors/relatives/friends, cofarmers, technicians and others. Co-farmers was reported to be the source of knowledge/information by the majority of alayon member respondents of Guadalupe (60\%), Anolon $1(50 \%)$, Anolon $3(62.5 \%)$, Cagnocot $(83.3 \%)$ and Madalunot (50\%). Likewise, neighbors/relatives/ friends were important sources of information about alayon system for the majority of the alayon group members of San Vicente $(50 \%)$, Bugho $(60 \%)$ and Diaz $(70 \%)$. Meanwhile, all and half of the Tabunok and Cagnocot alayon respondents, respectively, obtained such information from the technician assigned in their area. Only one from Anolon 2 and another from Diaz claimed to have gotten information from their brothers/sisters. Grandparents and parents were reported also by several alayon group member-respondents as their source of information regarding alayon system, while a few learned from others (PTA president and Farmers' association).

\section{Reasons for Involvement In Alayon Groups}

A number of alayon member-respondents reported several reasons for the formation of alayon organizations. The reasons given are: in order to allow simultaneous cultivation of farms, enable them to cultivate a much greater farm area with a greater farm harvest in mind, to hasten completion of farm operation/work, to earn additional income/immediate income, to exchange labor and establish a spirit of cooperation, to save the money that could have been used to hire laborer, lessen or lighten the burden of farm work and others (uplift living condition, availment of loan, no draft animals to use and to become an officer of the organization). 
Table 2. Distribution of respondents by alayon group according to the period around which they first learned about the alayon system

\section{CATEGORY}

\begin{tabular}{|c|c|c|c|c|c|c|c|c|c|c|c|c|}
\hline \multirow[t]{2}{*}{ Alayon Group } & \multicolumn{2}{|c|}{$\begin{array}{c}\text { Before } \\
\text { 1950's }\end{array}$} & \multicolumn{2}{|c|}{1950 's } & \multicolumn{2}{|c|}{1960 's } & \multicolumn{2}{|c|}{1970 's } & 1980 's & \multicolumn{2}{|c|}{1990 's } & \multirow{2}{*}{ Total } \\
\hline & & $\%$ & $n$ & $\%$ & $n$ & $\%$ & $n$ & $\%$ & $\%$ & $n$ & $\%$ & \\
\hline & & 20 & 1 & 6.7 & 6 & 40 & 4 & 26.7 . & - & 1 & 6.7 & 15 \\
\hline & & & & & 3 & 75 & & $-\quad$. & - & 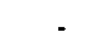 & & \\
\hline & & 16.7 & 2 & 33.3 & 1 & 16.7 & 2. & 33.3 & - & - & & \\
\hline & is & 50 & - & & 2 & 33.3 & 1 & 16.7 . & - & & & \\
\hline & & 62.5 & 3 & 37.5 & - & - & - & $-\quad$ & & & & 8 \\
\hline & - & - & - & - & - & - & - & - & 121 & $00-$ & & 12 \\
\hline & - & - & - & - & & & - & . & & 19 & 100 & 19 \\
\hline & . & & - & & 1 & 16.7 & 4 & 66.6 & & 6.7 - & & \\
\hline & 7 & 20.5 & 11 & 32.4 & 4 & 11.8 & 8 & & & $1.8-$ & - & \\
\hline & & 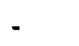 & 3 & 21.4 & 4 & 28.6 & 1 & 7.1 & & 5.11 & 7.1 & 14 \\
\hline & 1 & 10 & 1 & & 1 & & & 40 & & - & - & \\
\hline & 1 & 10 & 2 & 20 & 2 & 20 & 2 & 40 & 1 & $0-$ & & \\
\hline & - & & 1 & 7.7 & 3 & 23.1 & 2 & 15.4 & & 6.11 & 7.7 & \\
\hline & - & - & 1 & 8.3 & - & - & 1 & 8.3 & 10 & $3.3-$ & - & 12 \\
\hline Cababto-an & - & & - & - & 1 & 33.3 & & . & 2 & 6.7 & & 3 \\
\hline & 22 & & 25 & & 28 & & 29 & & 41 & 22 & & 167 \\
\hline
\end{tabular}

\section{Alayon in Technology Development and Transfer}

\section{Agricultural Technology/lnformation Learned or Acquired}

Through the alayon, farmers have often gained access to agricultural technology/information. Most notable among these are the selection of planting materials/seed varieties, fertilizer/pesticide application (amount, kind, method, time), contour farming, intercropping and techniques in land preparation, which were reported by respondents from most of the alayon groups studied. 
Dike making was especially learned by respondents in Cagnocot, San Agustin and Cababto-an. Specific technologies were specially learned by specific alayon groups.

The alayon member-respondents disseminated technology/information to help co farmers, let other farmers learn or try the technology on the farm, for better yield/production and in recognition of the technology's benefits.

\section{Common Methods of Technology Transfer}

The most common methods employed by alayon member on technology transfer are informal talk, training/seminars/farmers' classes and actual field observation/demonstration. Informal discussions were usually undertaken during off-farm activities, meetings called by technicians, farmer leaders, and farmers and house visitation wherein farmers could interact with each other and exchange ideas.

Other common methods of technology transfer employed by the alayon members was to try the technology on farmers' fields in order to let the farmers test the technology in his own farm. Farm and home visitation also enabled the farmers to learn technologies in interaction with all members of the family. Farmers also learned technologies through teaching by other farmers/parents. The radio was a good source of technology information as it can reach distant farmers. Pamphlets provide guides to the farmers on farming techniques. Giving farmers reading materials related to farming would be an important source of information for the farmers to learn. 


\section{IMPLICATIONS}

As an indigenous rural organization, alayon has voluntary membership which is motivated by the member-respondents' desire to undertake simultaneous cultivation of farms with much greater area and harvest and to lessen the burden of farm work. An equivalent amount of services (in terms of number of hours per day) is advocated by group members in all farm activities following the principle of symbiosis.

Cost efficiency was the major economic benefit derived from joining the alayon organization as money is saved with the system of exchanging labor. Other forms of benefits perceived by the members included the temporary relief from domestic worries, lessened exposure to sunlight, availment of mutual assistance and the spirit of cooperativism.

Through the alayon, farmers have gained access to agricultural technology which are in turn disseminated to co-farmers by informal conversation, farm visits and demonstration. However, it is not without constraints and one major deterring factor is financial in nature.

It is implied that alayon as an informal, indigenous rural organization, is essential in any rural development program. Therefore, farmers and rural populace are encouraged to form such indigenous rural organization to speed up effective technology development and transfer with the least cost but of utmost effectiveness. 